\title{
Trazos urbanos: miradas glocales en la ciudad de Toluca
}

\author{
Edith Cortés Romero \\ (Facultad de Ciencias Políticas y Sociales de la \\ Universidad Autónoma del Estado de México, México)
}

Recibido: $29 / 3 / 2015$

Aprobado: 25/6/2015

\begin{abstract}
Resumen. En el presente artículo, se busca comprender la evolución de la ciudad de Toluca en el marco del actual gobierno, para posicionarla como una ciudad global. Pensar las ciudades como acontecimientos públicos es mirarlas como un espacio de comunicación, con una configuración heterogénea, dinámica y tensionada por un conjunto de procesos de carácter local y global. La tríada ciudad-radio-jóvenes representa una guía para acercarnos a lo que sucede en el espacio urbano. En una ciudad que aspira a entrar a las denominadas ciudades globales; donde la Toluca de ayer, de hoy y de mañana ha visto pasar decenas de generaciones, unos acarician ilusiones, otros que soñaron con el futuro, algunos que viven el presente.
\end{abstract}

Palabras clave: glocal / ciudad / sonidos / jóvenes / espacio

\section{Urban Traces: Glocal Views of Toluca City}

Summary. This paper aims at understanding the evolution of Toluca city during the current governmental framework in order to situate it as a global city. To think of cities as public events means that they are conceived as spaces of communication, with a heterogeneous and dynamic configuration imbricated in a set of local and global processes. The triadic relationship city, radio and youth is a guide that allows us to get closer to what goes on in urban spaces. In a city that aspires to become a "global city", in which the past, present, and future Toluca city has seen dozens of generations pass; some who idealize illusions, others that dream about the future, and others just live the present.

Key words: glocal / city / sounds / youth / space 


\section{Introducción}

7 Toluca es un espacio de encuentros y desencuentros entre sus habitantes, donde se conjunta lo global con el toque local. Para comprender mejor este postulado, el eje guía del documento es el establecimiento de la radio en Toluca, medio que acompañó e integró las dinámicas locales. Se parte de los años treinta, fecha del surgimiento de la radio en la ciudad; después nos adentramos en la ciudad de Toluca durante el proceso de industrialización, lo cual implica que adquiera el carácter de zona metropolitana; posteriormente, por constituirse como la capital del Estado de México, la ciudad da un giro al sector servicios. Finalmente, se presentan algunos trazos juveniles sobre sus miradas glocales en el espacio urbano.

El Estado de México es el más poblado de la República mexicana, de acuerdo con el Consejo Nacional de Población (Conapo, 2014) cuenta con 16,6 millones de habitantes, lo que representa $14 \%$ de la población total del país. Tiene el primer lugar nacional en exportaciones de autopartes y automóviles; es líder en la producción florícola; y ocupa el segundo lugar nacional por su aportación al PIB con más de $10 \%$ anual; es el principal estado que aporta al PIB manufacturero nacional. En ese sentido, se destaca la entidad con 63 zonas y parques industriales al concentrar $18 \%$ del total de los desarrollos industriales del país. Su capital, Toluca, se sitúa en los $19^{\circ} 17^{\prime} 30^{\prime \prime}$ al norte y
0 horas, 1' 59, 97" longitud oeste del meridiano de México, y a una altitud de 2260 metros sobre el nivel del mar. Esto determina el clima prevaleciente, que va de templado a semifrío. La cabecera municipal de la ciudad de Toluca de Lerdo está integrada por 24 poblados.

Ramírez (2013) señala que en las ciudades latinoamericanas lo público está asociado en su mayoría a la búsqueda de referentes comunes en contextos urbanos. La experiencia urbana está marcada por distintas situaciones socioculturales y políticas; de ahí que para conectar las prácticas urbanas es indispensable conocer el habitar, en tanto que tiene que ver con la manera como la cultura se manifiesta en el espacio. Por su parte, De Certeau (1996) afirma que el espacio es un cruzamiento de movilidades, un lugar practicado precisamente por los pasos, la mirada y la acción del caminante, del transeúnte, del peatón, del observador.

\section{Un sonido glocal para adquirir una mirada sociocultural de Toluca}

¿Por qué pensar la ciudad desde los medios de comunicación, concretamente desde la radio? La radio siempre ha acompañado a sus radioescuchas, fenómeno al que no escapan los habitantes del valle de Toluca. A los medios de comunicación se les percibe como un factor de sensibilización en la sociedad. ¿Qué nos narra la radio?, 
¿Cómo se abordan los acontecimientos que generan una agenda?, ¿por qué suelen invitar a especialistas?, ¿por qué tratan el acontecer regional, estatal y nacional? Una primera respuesta a tales cuestionamientos es que la radio intenta informar a su audiencia en el acontecer público.

En Toluca, como en otras ciudades del país, la programación radiofónica es prácticamente musical; sin embargo, también se encuentran otros géneros que contribuyen con información para conocer los asuntos de coyuntura, del acontecer local, nacional e internacional. No obstante, la presencia de la radio fue determinante, pues gracias a ella las personas pueden estar presentes en todos lados y todos los acontecimientos de la ciudad: hogar, trabajo, calle, automóvil, autobús, etcétera. En otras palabras, la radio conecta y relaciona lo que acontece, o no acontece, entre lo foráneo y lo local (Monsiváis, 1987). Transitar la ciudad acompañado de los sonidos radiofónicos.

En Toluca, la radio ha sido un referente cotidiano, sobre todo para quienes no saben leer. La condición de lo público como lugar de disputas y conflictos urbanos tiene que ver con las desigualdades y distribuciones de acceso, temas que son abordados por las estaciones de radio; de igual manera, los anuncios resultan básicos, pues dan a conocer las noticias de las dependencias municipales y estales, así como del ámbito del entretenimiento con diferentes ofertas.

¿Qué pasa en el valle de Toluca en el siglo XXI, en este mundo globalizado?, ¿cómo se hacen visibles las realidades sociales, políticas y urbanas registradas en espacios locales, nacionales e internacionales? En el plano de la globalización, y específicamente de lo cultural, se hace referencia al eje global-local, donde se sitúan los procesos de mezcla de diferentes flujos y que conllevan un proceso de hibridación. La globalización implica la desterritorialización al ser procesos no lineales que provocan mecanismos de reterritorialización. De tal suerte que la globalización se considera glocalización, pues no se contrapone lo local a lo global, sino que se contemplan ambos ámbitos en un mismo plano integrado e interrelacionado ${ }^{1}$. La concepción de glocalización postulada por Robertson

1 El concepto de glocalización significa, pues, que mucho de lo que se declara a menudo como local (que se refiere a la apropiación de lo universal en contextos locales) no es sino la expresión de lo local en forma de recetas generalizadas de la globalidad. Así, lo local aparece como un producto global en el cual lo particular aparece como un aspecto de la globalización más que como su opuesto complementario. De este modo, toda una serie de fenómenos locales y localizadores -etnicidad, nacionalismo, movimientos indígenaspueden entenderse como productos globales, de modo que las mismas estrategias localizadoras son intrínsecamente globales. De manera que en el contexto global, la localidad es 
indica tanto la reinvención de la localidad como el doble fenómeno de la universalización del particularismo y la particularización del universalismo (lo local se manifiesta en lo global y viceversa), lo que ubica a la glocalización como fenómeno característico de la hibridación cultural (Citado en Hernández, 2013, p. 15).

\section{Los sonidos de la provincia se articulan con el sonido radiofónico}

Toluca creció en los años treinta ${ }^{2}$; al poniente empezaron a instalar a los políticos y gente de la época. Estos cambios contuvieron la construcción del gimnasio Agustín Millán, lugar donde se solían realizar los eventos sociales de tipo político, semioficial, hasta los bailes del Instituto Científico y Literario ${ }^{3}$ (Correa, 1980).

Entre 1930 y 1931, el sonido juvenil se presenta con la Liga de Estudiantes del Estado de México que luchaba contra el imperialismo y apoyaba causas populares; lo encabezaba Ladislao S. Badillo y Gabriel Luis Ezeta. Tal movimiento fue el antecedente de la autonomía del instituto. Génesis fue la publicación donde reseñaban sus actividades; no tuvo larga vida. También encontramos a los jóvenes en los eventos oficiales, como el desfile del 16 de septiembre por los festejos de la Independencia; en carros alegóricos se paseaban las jóvenes reinas y sus princesas en la zona de Los Portales.

El Estado de México no está entre las primeras entidades que tuvieran una frecuencia en el cuadrante. Radio Estrella $(\mathrm{XECH})$ inició transmisiones de manera experimental en 1937, una década después de que la radiodifusión surgiera en México ${ }^{4}$. La XECH es resultado de la llamada época de oro de la radiodifusión, cuando el medio "vino a ser el advenimiento de una nueva era en la que los medios de comunicación forman parte ineludible de la historia, como voceros de ideologías y acontecimientos" (CIRT, 1991, pp. 87-88).

continuamente reinventada, imaginada y reconformada. Culturalmente, esto significa un aumento de la conectividad, la no diferenciación entre lo global y lo local, así como un escenario de creciente hibridación global. Para mayor información véase Hernández (2013).

2 Los cronistas señalan que Toluca fue fundada por los misioneros franciscanos en marzo de 1522, y se convirtió en ciudad el 12 de septiembre de 1799, cuando la cédula real le concede tal categoría. El mejoramiento urbano, punto de encuentro entre modernidad y tradición, fue encabezado por José María González Arratia, con apoyo del ayuntamiento y del gobernador; para la traza urbana adoptaron el estilo neoclásico porfiriano, por el que las casonas venerables lucían su piel de piedra y sus interiores de pájaros y flores (Sánchez, 1991).

3 En marzo de 1956, el Instituto Científico y Literario se convirtió en la Universidad Autónoma del Estado de México.

4 Para ahondar en el tema, véase Cortés (2007). 
Diversos sucesos acompañaron el nacimiento de Radio Estrella: se fundó Radio Universidad Autónoma de México (XEUN); apareció la emisión gubernamental de mayor antigüedad: La Hora Nacional (25 de julio de 1937), durante el gobierno del presidente Lázaro Cárdenas (Álvarez, 1987); en 1938, Radio Universitaria de San Luis Potosí comenzaba sus emisiones; el 15 de diciembre de 1941 surgió la Cámara Nacional de la Industria de la Radio y Televisión (Cirt), en la que se agrupan los empresarios radiofónicos para preservar sus intereses. Por otra parte, se fundan los periódicos de gran tradición: en 1947, El Sol de Toluca, por Mario Vázquez Raña, y, en 1950, el Heraldo de Toluca, por la familia Mena.

El Estado de México en la década de 1930, contaba con 990112 habitantes, con una población económicamente activa de 302 754; además de una sociedad involucrada en el embate cardenista, el reparto de la tierra estaba en pleno apogeo; la ola izquierdista y socialista estaba muy en boga. En lo político, se dilucida el plan sexenal que se observa como un cáncer del socialismo. La corriente cardenista en el Es- tado de México no pasó de una fuerte distribución de propaganda. En lo educativo se establece en Toluca la Escuela Normal Mixta5 (1936-1949), fusión de las escuelas normales para Señoritas y para varones; se robustece la Escuela de Artes y Oficios y el Instituto Científico y Literario inicia el debate respecto a su autonomía. En esta etapa la ciudad de Toluca era pequeña, lo que facilitaba la interacción entre los estudiantes de estas tres instituciones para hacer propuestas alternas al sistema oficial.

A pesar del clima político y social, en el Valle de Toluca la única señal local durante más de dos décadas fue Radio Estrella, estación claramente musical, que se movía alrededor de los artistas del momento; sus noticieros eran poco notables, los cuales eran reseñados por locutores de los programas musicales. Sobresale la hora del aficionado, que llegó a hacer época con la presentación de tríos y cantantes, entre ellos Los Panchos, que imitaba el trío profesional de la ciudad de México, Los Xochimilcas, de gran popularidad, y el del señor Luis Goñi, Enrique López Medrano era excelente imitador

5 El trabajo de la Normal se enmarcó en dos políticas educativas: una con orientación socialista, impulsada por el presidente Cárdenas; otra acorde con los gobernantes de la entidad. El ingreso de los alumnos en promedio era a los catorce años, y básicamente eran hijos de empleados de gobierno, aunque también ingresaban hijos de agricultores, comerciantes y obreros. La mayoría de los alumnos provenían de Toluca y de municipios como Tenango, Tenancingo y Tejupilco, así como de otras entidades, como Guadalajara, Morelos y Michoacán. 
de Agustín Lara. Sin duda alcanzaron la mayor popularidad cuando invitaron al señor Roberto Mendieta para que tocara sones huastecos con su violín, estilo musical que posteriormente gustó al público y proyectó al grupo a través de la radio local y en las emisoras de la ciudad de México. Los tríos Los Cascabeles y El Cantarrecio gozaron de popularidad entre los toluqueños (Zárate, 1980).

El sonido juvenil se hace notar en la segunda mitad de los años treinta, cuando un grupo de estudiantes universitarios, entre ellos, Clemente Díaz de la Vega y Benito Sánchez, iniciaron su propia radiodifusora clandestina: la XEXS, con un equipo obsoleto. Se distinguían porque interactuaban con la audiencia. Sin duda, era una alternativa radiofónica; sin embargo, al gestionar su permiso les fue negado. En Crónicas sin destino, Clemente Díaz refiere que esos precursores lograron establecer en el Instituto la primera estación de radio cultural. El gobernador Zárate Albarrán prometió a Díaz modernizar la estación de radio con nuevo equipo y una nueva planta. El destino tenía otros designios (Díaz, 2013).

Por la parte institucional, en 1939

se estableció La Hora de la República, en el periodo gubernamental de Wenceslao Labra, programa que funcionó por año y medio, siendo transmitido por radio a nivel nacional desde el palacio de gobierno del estado, por una transmisora de la ciudad de México. En esa propuesta mensual participaban mú- sicos toluqueños como Horacio Zúñiga, Guadalupe Barbabosa, Carmen Garduño (Zárate, 1980, p. 307).

Sánchez (1991) subraya que en los años cuarenta se inaugura el tiempo de los grandes centros escolares de nivel básico: el Justo Sierra y el Miguel Alemán. El gobierno municipal se encontraba comprometido con la educación y con los valores de la sociedad toluqueña.

Además, se reconstruye el drenaje y la red de agua potable, se abren los museos de Arte Popular y de Bellas Artes. En 1951 se inaugura la Concha Acústica, lugar destinado a eventos culturales y artísticos, localizada en Los Portales; en la apertura amenizó la Banda de Música del Estado de México.

Por otra parte, en este escenario sobresalen las personas de las rancherías que acudían a la ciudad de Toluca a surtirse de mercancías en la tienda del señor Gama. Compraban harina, frijol, café legal, canela, huevo, alcohol del 99 en lata de 20 litros, azúcar en marqueta que se partía con un hacha, según los gramos solicitados. Los dueños de esas pequeñas tiendas venían en su camión de redilas; en ocasiones traían a sus niños, quienes jugaban en Los Portales mientras degustaban de los dulces Tóficos y Tomys.

La radio la escuchaban en familia, sobre todo cuando transmitían eventos relevantes, como la pelea del boxeador mexicano Raúl el Ratón Macías, en 1955, quien luchaba por el campeonato mundial de peso gallo. 
En 1956 aparece la segunda radiodifusora del Valle de Toluca: XEQY Radio Fiesta, que seguía la programación de la industria musical, incorporando concursos, entrevistas y trasmisiones en vivo. Dentro de su propuesta se "trasmitía un noticiero llamado Panorama, el primer noticiero radiofónico comercial concebido como tal, el cual elaboran un grupo de maestros" (Ortega, 2000, p. 35).

El sexenio del presidente Ávila Camacho se conoce como el periodo estabilizador, el cual tenía dos ejes fundamentales: la industrialización que buscaba un crecimiento económico, la urbanización y el crecimiento de la clase media, y la política de pacificación que implicó el corporativismo, la cooptación y la coerción. Esa política de sustitución de importaciones implicó que el gobierno apoyara con subsidios y medidas de protección a esa industrialización. El proceso de urbanización en la ciudad de Toluca se inicia a finales de los años cincuenta, lo que generó un proceso continuo de concentración de empresas y población en el corredor industrial Toluca-Lerma

En la década de los sesenta, el espacio urbano de la ciudad de Toluca sufre un cambio notable en la música popular, debido a la introducción de aparatos musicales electrónicos. De modo que un gran número de jóvenes aprovecharon para integrar conjuntos de rock como: los Topsy's, los Hearts's, los Intocables, el 2+3 y los Tiks. Iniciaron sus actuaciones en establecimientos públicos denominados café-cantantes: como el Memphis, en el pasaje Florida en 1965, el Ipanema, en la calle de Pino Suárez, el Pied Noir, en la calle de Morelos, el Zodiac, el Jaguicar, la Terraza, el Rey (Zárate, 1980, p. 309).

Sobresale también el apogeo de los grandes mercados de Toluca, entre ellos el 16 de Septiembre y el Hidalgo, donde las indígenas vendían jitomates y tortillas (Sánchez, 1991). A este último acudían los estudiantes de bajos recursos que venían de pueblos lejanos, para comer por dos pesos. Otros jóvenes visitaban Los Portales y pasaban al local donde vendían los moscos, los tradicionales licorcitos dulces que lograban emborrachar.

En cuanto a la música, Zárate (1980) menciona que para los años sesenta se puso de moda la sonora, la cual quiso igualar la popularidad de la que habían gozado las orquestas en los bailes; sus canciones fueron grabadas en discos y escuchadas en las radiodifusoras XECH, en Toluca, y XEW, en la ciudad de México.

La tercera emisora que surgió en Toluca fue Radio Celebridad XHTOM, en 1967; fue completamente musical. En 1968, Radio Miled obtiene la concesión, y contaba con una potencia de mil watts; además, es la primera que transmitió para el Valle de Toluca en frecuencia modulada. En estas estaciones los radioescuchas, sobre todo los jóvenes, estaban atentos para conocer el nombre de los artistas que se pre- 
sentaban en el evento llamado "Lluvia de Estrellas", que tenía lugar en el cine Rex, o bien se informaban del programa de artistas que se presentarían en el Salón Azul y Rosa o en el Motel del Rey, ubicado en la calle de Lerdo. Otro lugar importante era el Te Danzante, abría de las cinco a las doce de la noche, el reservado de mesa tenía un costo de 30 pesos y la entrada de 50 pesos. Había tres escenarios que presentaban diferentes grupos, era tiempo del rock, danzón, gogó, mambo, twist. Concepción Romero (2014) recuerda:

Bailábamos al ritmo de César Costa, Enrique Guzmán, Angélica María, Manolo Muñiz, Johnny Laboriel, los Teen Tops, Los Rebeldes del Rock, Pérez Prado, la Sonora Santanera, Gamboa Ceballos, Acerina y su Danzonera. La pasábamos bailando, sólo tomábamos Coca-Cola, Pepsi Cola, Jarritos o Lulú.

Los cambios continúan en Toluca, en la década del sesenta se principia con la industria automotriz en el corredor industrial Toluca-Lerma, con una política económica proteccionista para un rápido crecimiento. Destacan la empresa armadora Nissan (1961); General Motors (1962), una de las empresas productoras más importantes del país; VAM (1964), armadora automotriz mexicana que deja de funcionar en 1986; Automotive Moulding; Celanese Mexicana, dedicada a la producción y comercialización de fibras sintéticas y artificiales; Poliuretanos, fábrica de espuma de poliuretano utilizado para el sector automotriz, mueblero, tapicero, colchonero y zapatero; Playtex Apparel México, filial de la transnacional Sara Lee; Express Sinaloa, empresa dedicada al transporte público federal de carga.

En 1972 se expide el decreto de descentralización industrial, debido al incremento demográfico en la ciudad de México, por lo que la industria se concentró en otros estados. Se consolidan las zonas urbanas y contrastan con las cada vez más precarias zonas rurales. Había entonces 188000 habitantes en el municipio de Toluca, con una población económicamente activa de 60000 y 128000 inactivos.

En esta década y la siguiente hay una consigna contra la juventud del sector popular urbano: se ve como una amenaza; por lo que hay que vigilar, castigar y reprimir. El sector de políticos locales estuvo a favor de una ola moralizadora de los medios locales. De ahí que se procura

la imagen institucional, la del joven (felizmente) integrado, escolarizado y deportista que refleja la condición de los jóvenes de los sectores altos y medios y, en todo caso, las expectativas que las instituciones tenían sobre sus jóvenes - como esperanza de cambio- ocultando la diversidad de realidades juveniles en ese momento (Urteaga, 2010, p. 49).

Para 1969, la XEQY brindó su espacio a un grupo de estudiantes de la Facultad de Humanidades, con un programa semanal, cuya duración era de treinta minutos, y contaba con cuatro secciones: deporte, sociales, cultura y una radionovela. Su permanencia fue de dos años. 


\section{La industrialización de Toluca}

La llegada de la industria a la zona metropolitana de la ciudad de Toluca (ZMCT) implicó un proceso mayor de población, sobre todo en la periferia de la ciudad. Baca y Castillo (2005) afirman que el proceso de metropolización de Toluca se inició en la década de 1970, al conurbarse los municipios de Toluca y Metepec. En 1980, al proceso de metropolización se integró Zinacantepec y la población de la zona llego a 500000 habitantes.

La década de los setenta se inauguró con la apertura de la terminal de autobuses de Toluca que conectaba con las principales ciudades del país; se desarrolló la primera fase del circuito Tollocan con el propósito de agilizar la circulación vial; se abrió el mercado Benito Juárez con su gran explanada para el tianguis de los días viernes, donde la ropa de marca era más barata.

En 1972 nació Radio Principal, el antecedente de Sonido Ultra, la cual fue la primera estación de la República Mexicana del grupo Estéreo Rey. Radio Principal la inició la familia Zorrilla Martínez, posteriormente cambió su nombre por FM Globo; el cambio logró enormes beneficios para la estación; su programación se basaba solo en música en español y alcanzó una gran aceptación con el lema "Música en tu idioma" (Ortega, 2000). La voz oficial de la estación era del locutor Luis Heredia - con su frase "FM Globo Stéreo"-, quien acompañaba a su público con baladas románticas en es- pañol, interpretadas, entre otros, por Emmanuel, Paloma San Basilio, Daniela Romo. Con base en las peticiones de los radioescuchas, armaban la programación; los sábados se pasaba una lista de popularidad de veinte éxitos (Galván, 2013).

En esta década la música tuvo un gran impulso por parte del gobernador Hank González, quien apoyó la formación de la Orquesta Sinfónica del Estado de México, con su aún director Enrique Bátiz. Asimismo, surge la primera Banda Juvenil de Marcha, integrada por alumnos de la Escuela Normal n. ${ }^{\circ} 1$ (Zárate, 1980).

Toluca ya era una ciudad de contrastes, había estudiantes que tenían que trabajar para pagar sus estudios, por lo que se ocupaban como cargadores en el mercado o taxistas nocturnos, hacían traslados de las personas que salían de las fábricas a sus pueblos. El servicio de camiones contaba con ocho rutas, eran autobuses viejos; cobraban 25 o 40 centavos, dependiendo de la ruta.

Baca y Castillo (2005) refieren que la zona industrial se consolidó en los años ochenta; el corredor industrial Toluca-Lerma generó una importante oferta de empleo, la cual propició el surgimiento de nuevas colonias. Desde entonces, la ZMCT mantiene una dinámica en ritmo de crecimiento poblacional y económico. Así, Toluca se convirtió en la cuarta economía más productiva del estado, sólo después de Naucalpan, Tlalnepantla y Ecatepec. Para fines de 1970, el problema de la 
región se volvió urbanístico; la región metropolitana del norte había crecido desmesuradamente: 200000 personas vivían en la pobreza, lo que significaba 30000 jefes de familia.

El impulso hacia la industrialización provocó la atracción laboral. Las familias migraron del interior del estado y del país, lo cual generó demandas educativas y recreativas para los jóvenes y los niños; además del establecimiento de muchas vecindades, las menos agraciadas se ubican en el norte, a espaldas del Palacio de Gobierno, como Santa Bárbara, San Miguel, El Reflejo, La Teresona. Las vecindades eran construcciones grandes, como laberintos, con uno o dos patios, no había baños; sin embargo, en un cuartito de tres por tres vivían dos familias. Por supuesto, se generaron serios problemas de salud; en 1975 el Instituto Mexicano del Seguro Social (IMSS) realizó una campaña de detección de sarna.

Para este periodo, Urteaga señala, para el caso de los jóvenes, que

producto del contagio libertario de los estudiantes del 68 y Avándaro 71, un grupo heterogéneo de estudiantes organiza un proyecto alterno para abrir la universidad local ante un enorme número de aspirantes rechazados en el nivel medio superior: la Preparatoria Popular Toluca [... el 13 de septiembre de 1972] a partir de la reelección del rector de la UAEM distintos grupos de estudiantes inician una huelga de hambre y cada hora rompen un envase de Coca-Cola como símbolo contra el imperialismo [...] Experiencia que formaron parte de la rebeldía estudiantil que explotaría entre 1976 y 1977, movimiento que paralizó por siete meses la UAEM (2010, p. 51).

La película Un año perdido ${ }^{6}$, de Gerardo Lara, filmada en 1993, retrata lo sucedido en Toluca en los años setenta. La producción tuvo el apoyo del Instituto Mexicano de Cinematografía (Imcine) y de la Universidad Autónoma del Estado de México (UAEM).

La ciudad de Toluca contaba con bastantes zonas de terracería; hasta el periodo gubernamental de Alfredo del Mazo se pavimentaron sus calles principales con concreto. También se completó la urbanización con el alumbrado público, con arbotantes, iluminarias incandescentes, postes de concreto y ménsulas de tubo metálico, el cableado fue subterráneo (Correa, 1980, p. 279).

6 Esta película cuenta la historia de dos mujeres jóvenes provincianas, a partir de 1976: Matilde quiere ser dentista y Yolanda anhela ser cantante. Ambas enfrentan la autoridad paterna, viven el cambio de adolescentes a mujeres y comparten el despertar del sexo, el desafío a la autoridad, el conocimiento de las drogas y la conciencia política. Es una historia de amistad y liberación que culmina en la década de los noventas, cuando el tiempo las vuelve a reunir. Para mayores informes véase http://www.filmaffinity.com/es/film381927.html 
Junto con los años ochenta llegó el programa radiofónico Línea en Alta Tensión, que se transmite desde 1982, conducido por el licenciado y profesor Juan González Carbajal, en Súper Stéreo Miled (FM), cuyo contenido es de carácter social y además funciona como enlace entre la ciudadanía y las dependencias gubernamentales. $\mathrm{Al}$ inicio se transmitía por media hora, actualmente ocupa cuatro horas diarias. Su público es de sectores populares, ya que el locutor los ayuda a obtener una respuesta sobre los agravios públicos de que son sujetos. Con una inversión de 45 millones de pesos, el 18 de mayo de 1983, y después de siete años de gestiones, nace Radio y Televisión Mexiquense, a través de XHGEM. Ortega (2000) comenta que Radio Mexiquense fue la primera de carácter cultural en el estado y surge en un claro ambiente de oposición de los funcionarios e integrantes del partido oficial Partido Revolucionario Institucional, quienes creyeron que la propaganda priísta se haría solo a través de ese medio, por lo que perderían suculentas ganancias.

A diferencia de las frecuencias locales, Radio Mexiquense ${ }^{7}$ creó programas que abordaban diversos géneros: informativos, culturales, infantiles, de debate, de salud, entre otros, además de música "no comercial". Esto significó una indudable alternativa en el cuadrante para el auditorio.

Entre los programas infantiles sobresalen: Grillos Madrugadores y Bola de Niños. El primero es conducido por Juan Manuel Corona, mejor conocido como el Grillo Mayor, dicho programa tuvo el reconocimiento de la Unesco; se transmite de siete a ocho de la mañana, en el lapso en que los niños de preescolar y primaria se preparan para ir a la escuela. El Grillo Mayor manda los saludos de padres,

7 Para cubrir todo el Estado de México, Radio Mexiquense tiene tres repetidoras: Atlacomulco (XEATL 1520 AM), Tejupilco (XETEJ1250 AM) y Cuautitlán-Texcoco (XETUL 1080 AM). En mayo de 2003 se transmitió la señal por internet: http://www.edomex.gob.mex/tvmex. Para el 18 de mayo de 2008 se festejaron los veinticinco años de Radio Mexiquense, con la apertura de cinco nuevas emisoras y de cuatro estaciones de radio en Frecuencia Modulada (FM) y una más en Amplitud Modulada (AM): 1) XHGEM 91.7 FM Radio Mexiquense Metepec, con la cobertura en Santiago Tianguistenco, Mexicalzingo, Toluca, Santa María Rayón, Ocoyoacac, Zinacantepec, Chapultepec, San Antonio la Isla, Almoloya de Juárez, Santa Cruz Atizapán, Tenango del Valle, Metepec, Almoloya del Río, Tenancingo, San Mateo Atenco, Capulhuac, Xonacatlán y Lerma; 2) XHMEC 91.7 FM Radio Mexiquense Amecameca, con la cobertura en Amecameca, Ayapango, Ozumba y Tepetlixpa; 3) XHZUM 88.5 FM Radio Mexiquense Zumpango, con la cobertura en Zumpango, Tultepec, Tonanitla, Teoloyucan, Nextlalpan, Melchor Ocampo y Jaltenco; 4) XHVAL 104.5 FM Radio Mexiquense Valle de Bravo, con la cobertura en Valle de Bravo y Amanalco. 
tíos, abuelos a los niños y dedica las canciones. Ahora también se puede escuchar en internet con el eslogan "Tu compañero de la radio en la red". Este proyecto ha visto crecer generaciones: niños que ahora son padres o jóvenes que aún lo escuchan.

En 1981, el viejo mercado 16 de Septiembre se transformó en el Cosmovitral-Jardín Botánico. La oferta educativa en el nivel superior se amplía, al fundarse en 1986 el Colegio Mexiquense, A. C. ${ }^{8}$ y el Instituto Mexiquense de Cultura. En 1987, el gobernador Alfredo Baranda inauguró el Centro Cultural Mexiquense. Ese mismo año, en Metepec, se llevó a cabo la reunión de los Sistemas Estatales de Radio y Televisión, donde se establecieron convenios de intercambio en los campos de producción, capacitación, aspectos técnicos y operativos.

En 1989 nace Él y Ella y en 1992, Radio Lobo y O.K. 102. La primera difunde música en español e inglés; la segunda, música grupera, y la tercera, música en español. En 1992, Ultra 101.3 FM emitió su señal cuando se le otorgó la concesión a Arturo Zorrilla Martínez, del grupo Zoma Telecom. Al igual que otras concesionarias se concentró en la transmisión de música $\mathrm{y}$ de algunos espacios informativos.

\section{La terciarización de la ZMCT}

En la década de los noventa la administración rehabilitó numerosas casas antiguas para convertirlas en museos, como el José María Velasco, el Luis Nishizawa y la Casa de las Diligencias, esta última, en 1993, es adquirida por el gobierno; más tarde, en 1999, entabla un convenio con la UAEM, para convertirlo en un espacio para actividades culturales; donde la población disfruta de dichas actividades, así como de cursos y talleres para niños, jóvenes y adultos.

Bajo la iniciativa del gobernador Emilio Chuayffet, la Secretaria de Desarrollo Social patrocinó el libro El Estado de México hoy (1995), el cual representó una ventana para conocer la opinión de un grupo de cien empresarios del estado, así como de sus actividades industriales, sociales y culturales. Se hace énfasis en la zona del Valle de Toluca-Lerma, que sobresale en las ramas industriales favorecidas por el tratado de libre comercio (TLC), sobre todo en el sector automotriz.

Por otra parte, en el Plan Regional Metropolitano (PRM), de 1993, se distinguen siete municipios que conforman la ZMCT: Lerma, Metepec, Ocoyoacac, San Mateo Atenco, Toluca,

8 El Colegio Mexiquense A. C. se funda por iniciativa del Gobierno del Estado de México y El Colegio de México, A. C., como una institución dedicada a la investigación y la docencia en el ámbito de las ciencias sociales y las humanidades. Sus instalaciones ocupan el espacio de la exhacienda Santa Cruz de los Patos (data del siglo XVII), en el municipio de Zinacantepec. 
Xonacatlán y Zinacantepec, además de catorce municipios del entorno. El proceso de inserción femenina en el mercado de trabajo se vuelve progresivo:

desde la década de 1980 se advertía que las mujeres estaban tendiendo mayoritariamente a insertarse en el sector moderno, estructurado en actividades asalariadas. Con la emergente liberación del comercio, y la industrialización orientada a las exportaciones, se ha tendido a privilegiar el trabajo femenino. La lógica de remplazo de mujeres por hombres en el trabajo asalariado está asociada con la reducción de costos y facilidades de explotación (Baca y Castillo, 2011, p. 59).

De acuerdo con el Plan Regional de Desarrollo Urbano (PRDU), de 2005, en la década de los ochenta, el sector secundario fue el más dinámico en la región; mientras que en los noventa lo fue el sector terciario, sin demérito del secundario, pues si bien se terciarizó la región, no disminuyó la dinámica del sector secundario, presentando tasas casi iguales de crecimiento. Algunos indicadores económicos muestran la especialización de la región por ramas: textiles, industria de la madera (muebles), papel, minerales, comercio, servicios de alquiler de bienes muebles, restaurantes y hoteles, así como servicios de reparación y mantenimiento.

Respecto a las unidades económicas del Valle de Toluca, se observa una dinámica importante, debido a que las unidades del sector secundario crecieron $98 \%$ y las del terciario $74 \%$ en el quinquenio 1993-1998. En lo que se refiere al abasto que tiene la ciudad de Toluca, el H. Ayuntamiento refiere que cuenta con una oferta de productos en 2412 locales y 740 bodegas, ocho mercados, una central de abasto y cerca de 26 tianguis y supermercados: Wal-Mart, Chedraui, Comercial Mexicana, Soriana, Súper Kompras y Garis.

En 1976 llegó al municipio de Tenancingo la primera tienda del grupo Garcés. En 1986 se abrió Súper Kompras, Surtienda y Acrópolis, bajo el lema de la satisfacción de ahorrar. El grupo Garcés siempre ha hecho avisos promocionales en las estaciones de radio.

En 1994, el grupo Pritsa obtuvo la concesión para echar a andar la estación que hoy se conoce como Cristal 93.3 en FM. En 1995, Radio Estrella fue vendida y pasó a formar parte del grupo MAC. Después, esta corporación cambió su nombre por el de grupo Radiodifusoras Capital, la cual cuenta con otras estaciones localizadas en otros estados, y ahora funciona como Radio Capital. En cuanto al grupo ACIR, podemos decir que en la actualidad maneja las estaciones que, hasta poco antes de finalizar la década de los noventa, eran propiedad del grupo Corporación Mexicana de la Radio Toluca, la cual poseía una serie

9 Datos obtenidos del Plan Regional de Desarrollo Urbano del Valle de Toluca, volumen I, 2005. 
de frecuencias en las ciudades de Pachuca, Puebla, Celaya y Querétaro. En 1998, el dueño decidió vender las cuatro correspondientes al Valle de Toluca (Radio Lobo, La Tremenda, Qué Bonita y Él y Ella) al grupo ACIR, propiedad del señor Francisco Ibarra. En 1999, dicho grupo corporativo tomó posesión de ellas, las cuales automáticamente se adecuaron al formato que maneja la corporación, aunque mantuvieron algunas características iniciales. Dentro de estas modificaciones se puede mencionar el del nombre de dos emisoras: Qué Bonita cambió a Inolvidable, y La Tremenda a Mix FM.

En 1992, la empresa Pritsa cambió su denominación por Grupo Siete e incorporó a la otrora Radio Celebridad, bajo el nombre de Estéreo 102. En septiembre de 1999, se realizó la Tercera Reunión de la Red Nacional de Radiodifusoras y Televisoras Educativas y Culturales, A. C., efectuada en Toluca, donde Radio UNAM pasó de miembro honorario a miembro activo.

El crecimiento de la ZMCT fue considerable: en 1900 constaba de 886147 habitantes; en 1995 la población era de 1 063230 habitantes; en 2000, de 1233471 habitantes; en 2005, de un 1361500 habitantes, y la proyección para 2011 fue de 1461159 habitantes. De acuerdo con datos del Instituto Nacional de Estadística y Geografía (Inegi), en 2000 , el índice rural fue de $6,26 \%$, y en 2005 se redujo a 6,1\%. El índice de urbanización pasó de 93,74 a 93,9\%, respectivamente (Inegi, 2005).
Mientras en la década de los ochenta y noventa la población de la ZMCT se incrementó en $33 \%$, los pobres aumentaron en $37 \%$. Las áreas de la ciudad donde se ubicaron los de menos ingresos fueron las de norte y poniente. Encontramos dos tipos de vivienda de grupos populares de menos ingresos: las barriadas y las vecindades. La primera es el espacio urbano donde se localizan grupalmente los pobres, llegan al lugar al ser expulsados de su antigua residencia. Es el caso de La Teresona, asentamiento sobre cerros, por lo cual no se permite la construcción de calles y servicios públicos; sus habitantes eran personas originarias de Toluca, sin muchos estudios y subempleada; el promedio de habitante por vivienda era de ocho miembros. Se acarrea agua, se roba la energía eléctrica. Mientras que la vecindad es un conjunto de viviendas de renta baja que, en torno a un patio, obligan a los inquilinos a la convivencia y a compartir servicios vitales. Normalmente son casas viejas abandonadas. Las primeras vecindades aparecieron en el barrio del Cóporo y en la Retama, así como en los municipios recién conurbados a Toluca. Para estos años el promedio de renta era de 400 pesos. Las cortinas eran el medio alternativo para lograr cierta privacidad.

En 2004, Toluca registraba más de 27000 unidades económicas comerciales (tercer lugar en el estado), lo que representa 7,5\% del estado. En ellas se tenía ocupado al $10 \%$ del personal del Estado de México, percibiendo 14,7 \% de las remuneraciones del sector en el 
estado. La producción bruta del sector contribuía con $16,6 \%$ del total estatal, y el total de los activos fijos representaba $24,5 \%$ del índice del estado $(\mathrm{H}$. Ayuntamiento de Toluca, 2006).

En 2005, la estación $102.1 \mathrm{FM}^{10}$ cambió de formato a Neurótica FM, con el eslogan: "La radio para las grandes minorías", y contaba con conductores exradiactivos ${ }^{11}$. Tuvo una gran aceptación por la población juvenil y representó una propuesta diferente para el Valle de Toluca, pero solo duró hasta 2009, pues el Grupo Siete decidió cambiar nuevamente el formato a Los 40 Principales, que actualmente continúa.

Por otra parte, la Red de Radiodifusoras y Televisoras Educativas y Culturales de México, A. C., es una asociación civil constituida en noviembre de 2005 -tiene como antecedente la Red Nacional de Radiodifusoras y Televisoras Educativas y Culturales-; cuenta con 57 afiliados, de los cuales 56 son sistemas de radio y televisión públicos (gubernamentales, de instituciones educativas y de la sociedad civil) y Satmex, socio eventual con carácter honorario ${ }^{12}$. Para el caso del Estado de México el Sistema de Radio y
Televisión Mexiquense y UniRadio, de la UAEM, son socios activos de la red.

En el periodo presidencial municipal panista en Toluca (2006-2009), encabezado por Juan Rodolfo Sánchez Gómez, se contaba con 94 áreas verdes, de las cuales 10 son parques, 38 jardines y 22 áreas abiertas con vegetación. A principios de 2007 se decidió remodelar el centro de Toluca, con el objetivo de volverla una ciudad turística. Para 2008 se presentó un plantón de vecinos por la llamada apertura de los parques públicos como parte del programa federal de recuperación de los parques públicos, en el municipio de Toluca. Además, tuvo lugar el Primer Festival Toluca 2008, una celebración artística y cultural.

Por otra parte, en el Plan de Desarrollo 2005-2011 se afirma que el Estado de México cuenta con

664 bibliotecas públicas, con más de 2.5 millones de volúmenes y 9 millones de usuarios al año. Es un estado con una sólida infraestructura cultural integrada por 125 archivos históricos municipales y uno estatal con cerca de 20 millones de documentos. También cuenta con 27 museos administrados por el Instituto Mexiquense de Cultura, múltiples sitios

10 La estación 102.1, con su lema: “Cañón 102 música grupera”, duró de 1996 a 1999; Estéreo 102.1, “La emoción del recuerdo", de 1999 a 2005; Neurótica FM, “Radio para las grandes minorías", de 2005 a 2009, y Los 40 Principales, “Toda la actitud", de 2009 a la fecha.

11 Radio Activo fue una estación localizada en la ciudad de México, operó de 1993 a 2004, por su formato creativo fue de gran importancia para la juventud mexicana.

12 Para mayor información véase http://www.lared.org.mx/conoce-a-la-red.html 
arqueológicos, monumentos, arquitectura y pinturas rupestres con valor histórico (p. 39).

Respecto al transporte urbano, el $\mathrm{H}$. Ayuntamiento de Toluca (2006) refiere:

El Municipio de Toluca y su zona metropolitana presentan severos problemas en su movilidad urbana, a través de los años se han acumulado errores en la infraestructura y en la gestión de la vialidad. Llegando hoy en día a una distribución modal donde $51 \%$ de los viajes se resuelven en transporte privado, $35 \%$ en transporte público, $4 \%$ en taxis y $10 \%$ restante en otros modos. Esta distribución modal es parte de los problemas y han aumentado la responsabilidad de las autoridades municipales de la zona metropolitana sobre la mejora de estos y su impacto en los ecosistemas del Valle de Toluca.

De acuerdo con el diagnóstico del Plan de Desarrollo 2011-2017, el desempleo en el Estado de México tiene características únicas; sobre todo en las últimas décadas por las presiones sobre el mercado de trabajo, por la inmigración proveniente de otras entidades federativas que se han asentado en las zonas metropolitanas del Valle de México y del Valle de Toluca. Otro factor determinante ha sido la desaceleración del crecimiento de la economía estatal. Para 2000 y 2003 la tasa media de crecimiento real del PIB mexiquense fue de $0,13 \%$, muy por debajo de la de crecimiento demográfico (1,5\%).

En 2007, la UAEM inauguró UniRadio en el 99.7 de FM, una estación permisionada bajo la modalidad de noticias y reportajes del quehacer universitario:

En el nueve nueve punto siete, nos hemos convertido en referente radiofónico en el Estado de México, transmitiendo las 24 horas del día, los 365 días del año. Somos la estación de la Universidad Autónoma del Estado de México, que te acompaña, te orienta y te informa a través de música, programas de servicio, noticias, agenda cultural y difusión de la ciencia, la tecnología y el arte (http:// www.uaemex.mx/uniradio/).

Una buena cantidad de jóvenes egresados de la Licenciatura en Comunicación, de la Facultad de Ciencias Políticas y Sociales, de la UAEM, se han incorporado laboralmente a esta estación de radio. En febrero de 2014 la estación celebró su aniversario; el director de UniRadio, Gastón Pedraza Muñoz, declaró que "la consigna ha sido en estos años de trabajo exaltar los valores culturales de la región además de posicionar una opción informativa, cultural, recreativa diferente; pues los contenidos están comprometidos con el servicio público" (García, 2014).

Las radiodifusoras del Valle de Toluca han tenido un papel destacado para informar a sus radioescuchas el acontecer local, nacional e internacional. Destacan los informativos, que en el caso de la radio de provincia sobreponen lo local a lo internacional; aunque en esos noticiarios o cápsulas se difunde y mantiene informada a la población. Por ejemplo, Radio Capital, 1040 de $\mathrm{AM}$, tiene el noticiario $\mathrm{Al}$ Instante, en 
tres emisiones; en su tercera emisión el locutor es Luis Pantoja, quien hace un recuento de lo ocurrido en el ámbito estatal durante el día y establece enlaces en vivo con algunos corresponsales que la radiodifusora tiene en la entidad. En sí, se trata de un resumen noticioso en el que el locutor expresa sus opiniones sobre lo sucedido.

Luis Pantoja - el locutor- realiza un monólogo en el que puede dar consejos de salud o recomendaciones laborales, hablar sobre el fútbol mexicano y los pronósticos rumbo a la liguilla final, expresando su beneplácito ante la eliminación del América de la mano del payaso de Cuauhtémoc Blanco, al tiempo de expresar su alegría por la eliminación de las mariposas de Morelia y su técnico el fanfarrón de Rubén Omar Romano, situando como su favorito rumbo a la liguilla y al campeonato del fútbol al Toluca (Cortés, 2005, p. 90).

La misma radio transmite Voces de Esperanza, de lunes a viernes, de nueve a 10 de la mañana, se trata de un programa de la Comisión Diocesana; su conductor es el padre Jorge Rosas, quien interactúa con sus radioescuchas por teléfono y suele invitar a sus seguidores para que a mediodía oren por la paz y el bienestar social.

La mayor parte de noticias y reportajes que ofrece UniRadio van encaminados al quehacer universitario. De ahí surge $A$ todo galope, conducido por Jesús Humberto López, centrado en comentar las acciones de los conjuntos y deportistas de la universidad en todas las ramas posibles, aunque tiene como estandarte principal los equipos de fútbol de segunda y tercera división y el equipo de fútbol americano de liga mayor (estas escuadras son los llamados Potros). Aunque también cuenta con una sección en la que se habla del deporte profesional nacional e internacional. El programa se transmite de lunes a viernes, de tres a cuatro de la tarde.

Después de este recuento sobre la radio en provincia, podemos resumir que los habitantes de la ciudad de Toluca utilizan este medio como compañía e instrumento de información. A través de los anuncios de las instituciones públicas o privadas, el público sabe oportunamente la cartelera de la lucha libre que se presenta los jueves en el gimnasio Agustín Millán, la exhibición de autos clásicos, la semana de librerías itinerantes que están en el centro de Toluca y que ofrecen grandes descuentos, noticias del H. Ayuntamiento de Toluca, las actividades de la Fundación Tláloc, A. C., de los paseos nocturnos en bicicleta, los festivales del centro histórico y de cine, las opciones para estudiar carreras técnicas, hasta las ofertas de tiendas como Garis o Súper Kompras.

\section{Los jóvenes: voces y miradas glocales en la ciudad de Toluca}

Los jóvenes que a diario realizan el recorrido por la ciudad de Toluca son de diversas edades y de diferen- 
te estrato económico. La pregunta que aquí surge cuando se mira andar por el espacio urbano a los jóvenes es ¿quiénes son y cómo hacen uso de este espacio urbano?

De acuerdo con Urteaga (2010), la generación de jóvenes del 2000 produce muchas imágenes de sí misma en diferentes ámbitos sociales y culturales de la vida mexiquense. La presencia y la agencia de los jóvenes es protagónica en muchos de estos. Por citar algunos ejemplos, encontramos a

los aficionados Toluqueños, $\mathrm{y}$ en especial a los de la Banda del Rojo (la barra que ahora identifica a la región), han transformado la manera de apoyar, o como dijeran en Centro y Sur América, de hinchar en este lugar, puesto que no son un grupo violento como tal, pero que al ser nombrados como barra, o ser identificados con la mascota del equipo (Club Deportivo Toluca), el Diablo, se genera un imaginario transmitido por los medios de comunicación, en donde se les ve como un grupo que amenaza el orden de los espectadores (Cortés, 2012, p. 323).

También están los espacios cotidianos en el centro de Toluca que indudablemente crean momentos extraordinarios dentro de la vida de los jóvenes durante la ceremonia de quince años. Los jóvenes utilizan su cuerpo como una forma de seducción y de comunicación entre pares, esos usos en tanto acciones que realizan en un espacio determinado. Siempre está presente ese doble juego, donde se cumple con las normas que señalan los adultos y a la par desarrollan sus propias reglas. Los jóvenes son tan dinámicos que no solo se apropian de los espacios, sino que también ocupan los que son creados para ellos.

Nombramos tres tipos de prácticas juveniles en el espacio urbano de la ciudad de Toluca: el parkour, la escena gótica y la música. El parkour (el arte del desplazamiento) tuvo su origen en la década de los ochenta; se trata de una disciplina cuyo objetivo es ir de un punto a otro superando los obstáculos que se presentan en su recorrido, la idea es desplazarse por el entorno de una manera rápida y efectiva utilizando las habilidades del cuerpo humano. José Ramón (2012) practica el parkour y expresa: "con los primos me ponía a saltar, eran muchas emociones, y una gran adrenalina, se disfruta y se libera de todo". Por su parte, José Luis (2012) manifiesta: "disfruto mucho andar trepando paredes, brincar una barda tiene su chiste y su técnica". Tal práctica es un deporte que les gusta y que por naturaleza debe desarrollarse en un ambiente urbano y debe practicarse mientras se es joven y se pueda. Uno de los problemas a los que se enfrenta este sector es que la gente mayor se opone a su práctica en Toluca, argumentando que pueden lastimarse y que es algo que sólo lo hacen los rateros.

Por su parte, la comunidad gótica expresa que los jóvenes se apropian de su cuerpo, que manifiestan su control sobre sí mismos. El color negro se 
asocia a la muerte, al poder y las manifestaciones de gloria; el maquillaje negro y pálido representa el estatus de la muerte. "Para uno como gótico primero está el conocimiento y luego la vestimenta. Nuestra cultura lleva una espiritualidad, un buscarse a sí mismo $\mathrm{Y}$ el presentarte de negro es parte de la esencia, es presentarte como la muerte" afirma Efrén Maldonado (2013). Ante la constante vigilancia, en especial a los de la escena oscura, los jóvenes se han organizado y llevado a cabo reuniones en lugares privados para socializar, sin ser víctimas del maltrato social por representar un sector que "desobedecen las normas" de los adultos. En 2013 celebraron el World Goth Day, en el bar La Muerte Chiquita $^{13}$.

Sobresale en el espacio urbano el género laser punk. Sar Morgue (2012), a partir de una computadora, hace pistas acompañado del teclado en las madrugas; la música es su medio de catarsis, no se mira en un futuro para dedicarse a ello, solo la disfruta y se relaja. El laser punk es un tipo de punk que incluye sonidos escandalosos con la batería, el bajo y echa mano de sintetizadores para lograr diferentes sonidos. Las canciones normalmente son cortas, duran entre un minuto y minuto y medio, pero son sumamente estridentes.
Los jóvenes expresan: si se quiere tener grandes experiencias hay que formarse un estilo propio. "Así es la juventud" de mi ciudad, del campo, de mi barrio, colonia, fábrica, unidad habitacional, mi calle; son siempre espacios ideales para que todo ocurra. Entre la multitud siempre se es anónimo y ser anónimo en la multitud da la oportunidad de aparecer y desaparecer al antojo de cada uno; no es que uno vaya por el mundo tratando de cambiarlo, sino solo hacerlo más cómodo, más auténtico y más libre. Pueden quebrarse la cabeza tratando de comprender cómo es que todos funcionamos al unísono pero acaso no es la realidad así, con tantos matices como se puedan, con tantos estilos de vida como la imaginación permita.

\section{Notas finales}

Pensar lo que son las ciudades como acontecimientos públicos es mirarlas como un espacio de comunicación. Reguillo advierte que "el desafío para la agenda de investigación es hacer visibles las mediaciones que intervienen en la configuración de un orden urbano heterogéneo, dinámico, conflictivo y tensionado por un conjunto de procesos de carácter local y global" (2000, p. 42).

13 La Muerte Chiquita es un bar localizado en la ciudad de Toluca, donde se organizan eventos, se presentan bandas, djs o exposiciones de artistas. Abrió sus puertas en febrero de 2011. 
En la sociedad actual del Valle de Toluca, los acontecimientos prácticamente se deslizan por los sistemas de comunicación, los cuales resultan ser los vigilantes de la información que se transmite, pues disponen cuáles son los temas que merecen la atención de la audiencia: política, economía, violencia, guerra, deportes, religión. De esta manera se convierten en los principales factores de sensibilización en la sociedad.

En provincia, la radio representa un aspecto fundamental para los habitantes, por ser un medio que les permite mantenerse comunicados respecto a lo que acontece en la ciudad. En las diferentes estaciones transmiten anuncios referentes al cambio de sentidos de las calles, el reporte del tráfico, las noticias del $\mathrm{H}$. Ayuntamiento, como la condonación de los cargos atrasados en el pago del agua. No se omite mencionar el papel que juega este medio en relación con los temas del gobierno, donde se nota un respeto exacerbado por la clase política de todo orden.

Ahora bien, de acuerdo con Licona (2009) el espacio público ha sufrido profundos cambios con la globalización; por tanto, la tradicional definición de espacio público ya no es del todo funcional, tendríamos que reconocer la constitución de otros espacios públicos y que el sentido de lo público ha tomado otros derroteros, pues ya no se comprende únicamente a partir de su espacialización.
En este sentido, en la ciudad de Toluca, en los tiempos globales, ha predominado la actividad relacionada con el sector del comercio y servicios, así como las relacionadas con la industria de la transformación. Esto debido a la expansión urbana, al desarrollo industrial y a la ampliación de las zonas habitacionales. Tampoco hay que olvidar que la ciudad es sede del aparato de gobierno estatal y municipal, lo cual implica una alta proporción de ocupación relacionada con la administración pública.

La tríada ciudad, medios y jóvenes ha representado una guía para acercarnos a lo que sucede en el espacio urbano de Toluca, donde consideramos que los jóvenes son una veta para acercarnos a los cambios que emergen en la ciudad. Ser joven es la gran aventura, es el despertar a una nueva etapa que albergará las mejores vivencias de nuestra vida, todo parece demasiado fácil cuando se es joven, todo demasiado pequeño por explorar. En el escenario de las ciudades y del campo, en la casa, en la escuela, en la calle, durante el trabajo, en el tiempo libre, en cada momento se configura la vida cotidiana, se desarrollan procesos de interacción, donde van creando sus formas de vivir la vida. Lo que hace imposible enmarcar características específicas que definan la "cotidianidad mexiquense"; sin embargo, es evidente que este "vivir día a día" es lo que da sentido y fortaleza a la gente que habita en el Estado de México. 
Toluca y el Estado de México de ayer, hoy y mañana han visto pasar decenas de generaciones: unas acarician ilusiones, otras soñaron con el futuro, algunas inconscientemente viven el presente, pero al fin y al cabo todas tienen algo en común, que va más allá de una etapa de la vida, de un proceso de saber, de un descubrimiento del mundo y una sed por vivir, se muestra una mirada cotidiana sobre lo cotidiano. Como lo señala Portal (2007), el espacio público no es neutral, es un escenario de conflictos y negociaciones; donde el estado es el garante para su uso, pero los grupos sociales establecen estrategias específicas por su uso, su significación, desplegando y recreando los referentes identitarios para su reproducción. Asimismo, los espacios considerados tradicionalmente como públicos: plazas, centros históricos, calles, cines, baños públicos, centros comerciales, son espacios privados de uso público.

\section{Referencias}

Álvarez, J. R. (Comp.). (1987). Radiodifusión. Enciclopedia de México. México: Coedición de la Enciclopedia de México y de la Secretaría de Educación Pública.

Baca Tavira, N., \& Castillo Fernández, D. (2005). Precarización ocupacional por género en Zona Metropolitana de la Ciudad de Toluca. Convergencia. Revista de Ciencias Sociales, 12(37), 289-326.
CIRT. (1991). La industria de la radio y la televisión en México (1921-1950). Tomo I. Comunicación y Sociedad. México: CIRT.

Conapo. (2014). Consejo Nacional de Población: Proyecciones de población de las entidades federativas de México.

Correa, H. (1980). Evolución urbana de Toluca. En A. Sánchez Arteche. Siglo y medio, sumaria tolucense. Toluca: $\mathrm{H}$. Ayuntamiento de Toluca.

Cortés Romero, E. (2005). La voz que articula y los oídos que imaginan el perfil de contenido que construye la radio informativa, deportiva e infantil en el Valle de Toluca. (Tesis de Maestría). Universidad Iberoamericana. México.

Cortés Romero, E. (2007). Un panorama histórico de la radio en el Valle de Toluca. La escena radiofónica. Espacios Públicos, 10(20), 415-439. Recuperado de http://www.redalyc. org/articulo.oa?id=67602023

Cortés Romero, E., Hinojosa, D., \& García, A. (2012). La banda del rojo de los diablos del Toluca. En R. Magazine, S. Martínez, \& S. Varela (Coords.), Afición futbolística y rivalidades en el México contemporáneo: una mirada nacional. México: Universidad Iberoamericana.

De Certeau, M. (1996). La invención de lo cotidiano 1: el arte de hacer. México: Universidad Iberoamericana-Iteso.

Díaz de la Vega, C. (2013). Crónicas sin destino. México: Gobierno del Estado de México. 
Galván, H. (2013). Rock impop: el rock mexicano en la radio Top 40 . México: Creative Commons Reconocimiento.

García, J. (1995). El Estado de México hoy. México: Gobierno del Estado de México.

García Conejo, M. (17 de febrero de 2014). UAEM celebra el séptimo aniversario de UniRadio. Portal. Recuperado de http://diarioportal.com/tag/investigaciones-academicas/

Gobierno del Estado de México. (2005). Plan Regional de Desarrollo Urbano del Valle de Toluca. En Gaceta del Gobierno. Toluca: Gobierno del Estado de México.

Gobierno del Estado de México. (2006). Plan de desarrollo 2005-2011. México: Gobierno del Estado de México. Recuperado de http://www.uaemex. $\mathrm{mx} /$ planeacion/InfBasCon/PD_ GEM_2005-2011.pdf

Gobierno del Estado de México. (1993). Plan Regional Metropolitano de Toluca. En Gaceta del Gobierno. Toluca: Gobierno del Estado de México.

H. Ayuntamiento de Toluca. (2006). Gaceta municipal especial. Plan de desarrollo municipal 2006-2009. Toluca: H. Ayuntamiento de Toluca.

Hernández, G. M. (2013). Glolugares: espacios singulares de la glocalización. El caso de Valencia. Kamchatka. Revista de Análisis Cultural, 2, 13-36.

Herrera, S. B. (1997). Globalización y desarrollo mundial. México: Editorial de Ciencias Sociales.
Inegi (Instituto Nacional de Estadística y Geografía). (2001). XII Censo General de Población y Vivienda 2000. México: Inegi.

Inegi. (2005). II Conteo de población y vivienda 2005. México: Inegi.

Licona, E. (2009). Etnografía del espacio público. Conferencia magistral dentro del Seminario sobre Estudios de Juventud en México, en la Universidad Autónoma del Estado de México, Facultad de Ciencias Políticas y Sociales (FCPyS). México.

Monsiváis, C. (1987). Entrada libre, crónicas de la sociedad que se organiza. México: Fondo de Cultura Económica.

Ortega, A. L. (2000). El tratamiento informativo en noticieros radiofónicos locales. Estudio de caso sincrónico: Hoy por Hoy y Así Sucede. (Tesis inédita impresa de licenciatura). Universidad Autónoma del Estado de México.

Portal, M. A. (2007). Introducción, espacio público y transformaciones urbanas. En M. A. Portal (Coord.), Espacios públicos y prácticas metropolitanas. México: Universidad Autónoma Metropolitana.

Ramírez Kuri, P. (2013). La ciudad desde el espacio público y las prácticas ciudadanas. En Ramírez, B., \& Padilla, E. (Comps.), Teorías sobre la ciudad en América Latina, vol. II. México: Universidad Autónoma Metropolitana, Unidad Xochimilco.

Red de Radiodifusoras y Televisoras Educativas y Culturales de México, A. C., (s. f.). Recuperado de http:// www.redmexico.org.mx/ 
Reguillo, R. (2000). Ciudad y comunicación. La investigación posible. En G. Orozco (Coord.), Lo viejo y lo nuevo. Investigar la comunicación en el siglo XXI. Madrid: Ediciones de la Torre.

Sánchez García, A. (1991). El ayer de Toluca. México: Gobierno del Estado de México. UniRadio. Recuperado de http://www.uaemex.mx/ uniradio/

Urteaga, M. (2010). La construcción de lo juvenil en el Estado de México. En Inspiración y compromiso: los jóvenes en el Estado de México. Toluca: Secretaría de Desarrollo SocialInstituto Mexiquense de la JuventudGobierno del Estado de México.
Zárate de Lino, I. (1980). Teatro y música en Toluca. En A. Sánchez García. Siglo y medio, sumaria tolucense. Toluca: H. Ayuntamiento de Toluca.

\section{Entrevistas}

Concepción Romero (2014). Los días de baile en la ciudad de Toluca.

Efrén Maldonado (2013). La muerte chiquita, el mundo gótico.

José Luis (2012). Una experiencia con el parkour en Toluca.

José Ramón (2012). Una experiencia con el parkour en Toluca.

Sar Morgue (2012). El laiser punk, un género musical. 